\title{
Two Echinostome Species, Pegosomum bubulcum and Nephrostomum ramosum (Digenea: Echinostomatidae), from an Eastern Cattle Egret, Bubulcus ibis coromandus, in Republic of Korea
}

\author{
Seongjun Choe', Dongmin Lee', Hansol Park', Hyeong-Kyu Jeon', Youngsun Lee ${ }^{2}$, Eunju Kim², Ki-Jeong Na², \\ Keeseon S. Eom ${ }^{1, *}$ \\ 'Department of Parasitology, Medical Research Institute and Parasite Resource Bank, School of Medicine, Chungbuk National University, \\ Cheongju 28644, Korea; ${ }^{2}$ The Wildlife Center of Chungbuk, Cheongju 28116, Korea; ${ }^{3}$ College of Veterinary Medicine, Chungbuk National University, \\ Cheongju 28644, Korea
}

\begin{abstract}
We describe 2 echinostome species recovered from an Eastern cattle egret, Bubulcus ibis coromandus, from Cheongju-si (city), Chungcheongbuk-do (province), Korea. Total 72 Pegosomum bubulcum specimens were recovered from the bile duct. They were $7,566 \times 2,938 \mu \mathrm{m}$ in average size and had 27 collar spines with vitelline extension from anterior $1 / 3$ level of the esophagus to mid-level of the posterior testis as characteristic features. Total 9 specimens of Nephrostomum ramosum were recovered in the small intestines of the bird. They were ribbon-shaped, $11,378 \times 2,124 \mu \mathrm{m}$ in average size, and morphologically variable in some organs, i.e., the number of collar spines (47-50), the shape of ovary and testes, and the extension of vitelline follicles. These morphological variations observed in a single host indicated that these features are not critical for the classification of Nephrostomum species and thus were reconsidered taxonomically as synonym of $N$. ramosum. This study is the first report documenting and describing both flukes and their associated genera in Korea.
\end{abstract}

Key words: Pegosomum bubulcum, Nephrostomum ramosum, Bubulcus ibis coromandus, echinostome, parasite, cattle egret

\section{INTRODUCTION}

The cattle egret, Bubulcus ibis (Family Ardeidae) is a piscivorous bird that is characterized by dull orange feathers on the chest and head regions during the breeding season. It exhibits a cosmopolitan distribution and feeds on various preys such as fish, insects, and frogs. The Eastern cattle egret, Bubulcus ibis coromandus, has a wide distribution ranging from Eastern Pakistan to Eastern Australia [1]. In the 1960s, the Eastern cattle egret was rarely observed in Korea, and almost all of its populations were observed only in the southern part of the Korean peninsula $[1,2]$. Today, however, it is commonly observed throughout Korea near rice fields, grass fields, and wetlands. It migrates to Korea only in the summer season (mid-April to

\footnotetext{
- Received 19 January 2016, revised 15 May 2016, accepted 8 June 2016.

*Corresponding author (kseom@chungbuk.ac.kr)

(C) 2016, Korean Society for Parasitology and Tropical Medicine

This is an Open Access article distributed under the terms of the Creative Commons Attribution Non-Commercial License (http://creativecommons.org/licenses/by-nc/4.0) which permits unrestricted non-commercial use, distribution, and reproduction in any medium, provided the original work is properly cited.
}

late September) [1]. Since the Eastern cattle egret, like other herons and egrets, has indiscriminate food habits, it is considered a host for many trematode parasites.

Cattle egret carries Pegosomum sp., Apharyngostrigea ardeolina, Metorchis ozakii, and Stephanoprora ozakii in Japan [3-6], and Aparyngostrigea ramai, Nephrostomum bicolanum, Pegosomum egretti, and Uroproctepisthmium taiwanense in Taiwan [7]. However, the helminth parasites of this avian species have never been reported previously in Korea. During the investigation for the avian helminth fauna of Korea, 2 unrecorded echinostome species, Pegosomum bubulcum and Nephrostomum ramosum, were recovered from an Eastern cattle egret, B. ibis coromandus. Therefore, we described the morphological and faunistic characteristics of these 2 echinostomes, and compared deeply with those of previous studies.

\section{MATERIALS AND METHODS}

A male B. ibis coromandus (WCC No.: 20140205) was found in June 2014 in the town of Cheongju-si (city), Chungcheong- 
buk-do (province), Korea, near its breeding colony. The egret was rescued and treated by the Wildlife Center of Chungbuk (WCC), but it died soon after. It was then transferred to the Parasite Resource Bank of Korea from the WCC for parasitological examination. In the autopsy of egret, 1 species of trematode was recovered in the biliary system and other trematode species was collected in the small intestines. The collected flukes were rinsed in phosphate buffer several times and placed with $10 \%$ buffered formalin under a cover glass with slight pressure for microscopic observation after staining with Semichon's acetocarmine. The various structures of the worms were observed under a light microscope and measured.

Abbreviations used in Tables and descriptions are as follows: BL: body length; BW: maximum body width; CL: collar length; CW: collar width; NCS: number of collar spine; OSL: oral sucker length; OSW: oral sucker width; PL: prepharynx length; PHL: pharynx length; PHW: pharynx width; ESL: esophagus length; CSL: cirrus sac length; CSW: cirrus sac width; SVL: seminal vesicle length; SVW: seminal vesicle width; VSL: ventral sucker length; VSW: ventral sucker width; OVL: ovary length; OVW: ovary width; MEL: Mehlis' gland length; MEW: Mehlis' gland width; ATL: anterior testis length; ATW: anterior testis width; PTL: posterior testis length; PTW: posterior testis width; EL: egg length; EW: egg width; FO: forebody length (distance from the anterior end to the anterior margin of the ventral sucker); U: uterine field length (distance from the anterior margin of the ovary to the posterior margin of the ventral sucker); and T: post-testicular field length. The size and proportions of the standard structures relative to the body length were calculated as described by Kostadinova [8]. Each propor-

Table 1. Morphometric comparison of Pegosomum bubulcum with other Pegosomum species

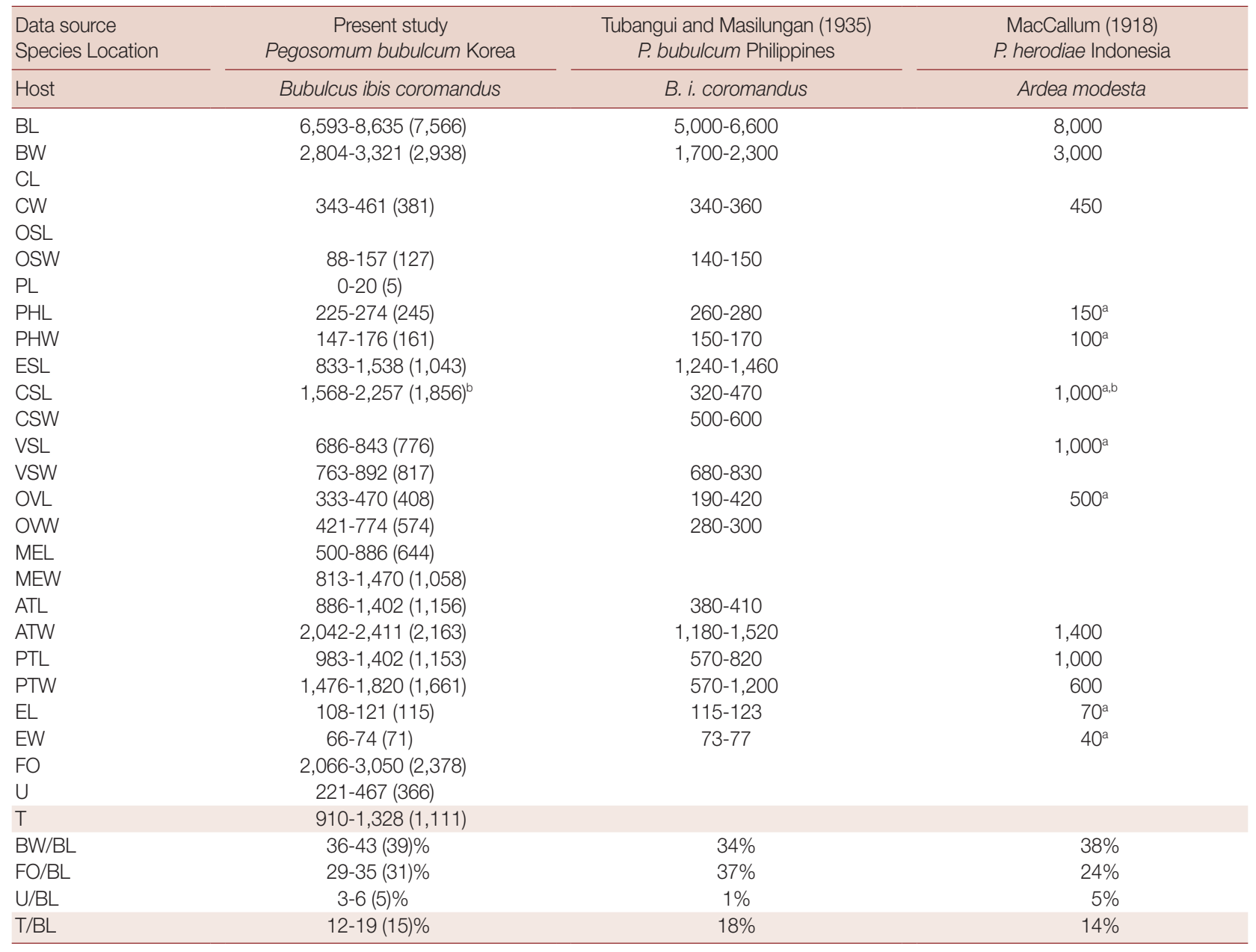

Measurements are in $\mu \mathrm{m}$.

aEstimated by present authors.

brojected cirrus sac length. 


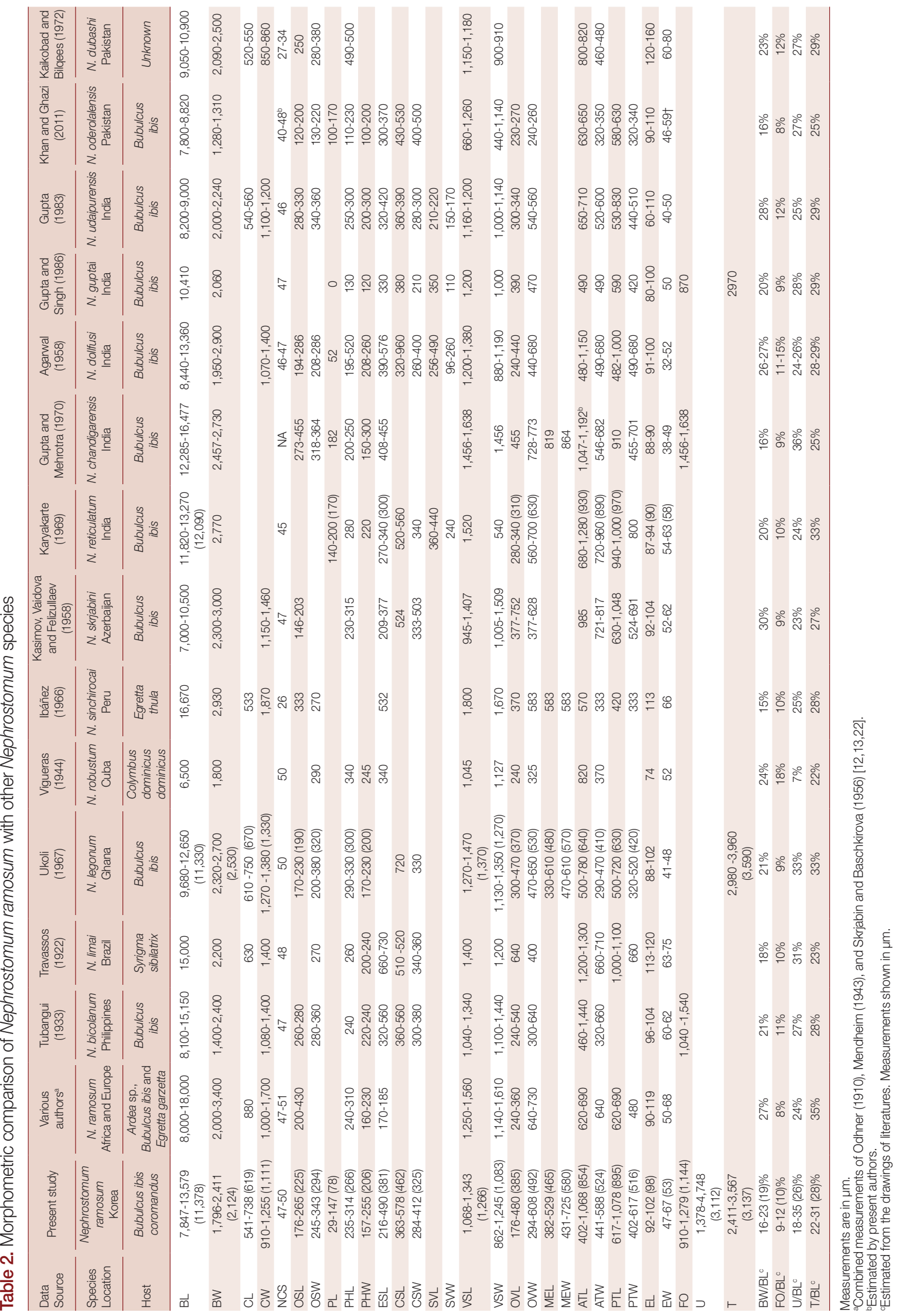


tion for previously described species was estimated from each drawing of the species. Measurements of the present specimens and those of previously described fluke species that resemble our specimens are shown in Tables 1 and 2.

\section{RESULTS}

\section{Recovery of worms}

Six parasite species were identified during parasitological examinations of the host. One was the echinostome Pegosomum bubulcum and 72 specimens of this species were collected from the ball-like bulge in the biliary system. These flukes were pinkish red. Two other echinostome species were found in the small intestine of the host, namely, Nephrostomum ramosum ( $\mathrm{n}=9$ ) and Echinochasmus japonicus $(\mathrm{n}=2)$. Other than trematodes, Desportesius invaginatus, Eustrongylides excisus, and an unidentified nematode species were also recovered in the proventriculus.

Family Echinostomatidae Looss, 1899

Genus Pegosomum Ratz, 1903

Pegosomum bubulcum Tubangui \& Masilungan, 1935

Materials examined: 20 of 72 specimens collected from a cat-
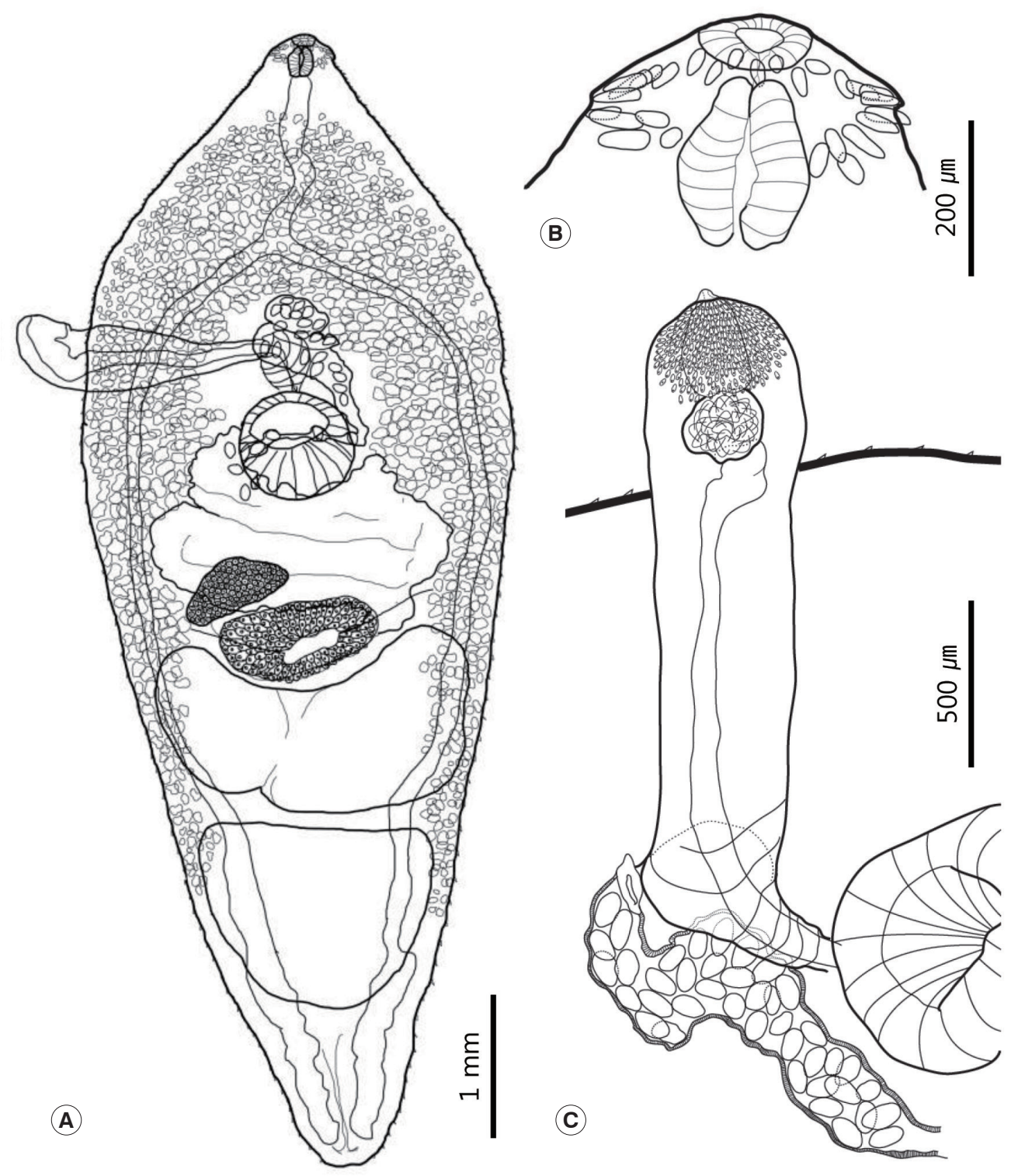

Fig. 1. Drawings of Pegosomum bubulcum specimens recovered from a cattle egret, Bubulcus ibis coromandus. (A) Whole body. (B) Head collar region. (C) Terminal genitalia with projected cirrus sac. 
tle egret, B. ibis coromandus, from Cheongju-si (city), Chungcheongbuk-do (province), Korea (GPS: 36 36'56.9"N 127 $\left.28^{\prime} 54.9 " \mathrm{E}\right)$. Two of the specimens were deposited in the National Institute of Biological Resources in Korea (NIBR) (NIBR specimen no. KOSPIV0000221885 and KOSPIV0000221886).

The morphological characteristics were described with 20 intact mature adults (Fig. 1). Morphometric measurements of their features are provided in Table 1. Body medium sized, plump, and leaf-like. Maximum width of the body at the level of the ventral sucker $(\mathrm{BW} / \mathrm{BL}=36-43 \%)$. Tegument covered with minute spines, which distributed in the whole body and their density decreased posteriorly (Fig. 1A). Head small with a weakly developed head collar. Oral sucker subterminal to terminal, subspherical, and surrounded by 27 collar spines. Four pairs of angle spines slightly larger than the other spines, 79-92 (86) long and 15-20 (17) wide. Lateral spines 55-69 (63) long and 12-17 (14) wide. Dorsal spines arranged in double rows, 50-60 (53) long and 10-15 (12) wide (Fig. 1B). Prepharynx short. Pharynx strongly muscular, had an elongated oval shape, and larger than the oral sucker (Fig. 1B). Esophagus had minute diverticula that obscured in most specimens. Forebody very long $(\mathrm{FO} / \mathrm{BL}=29-35 \%)$. Ventral sucker relative-
(A)

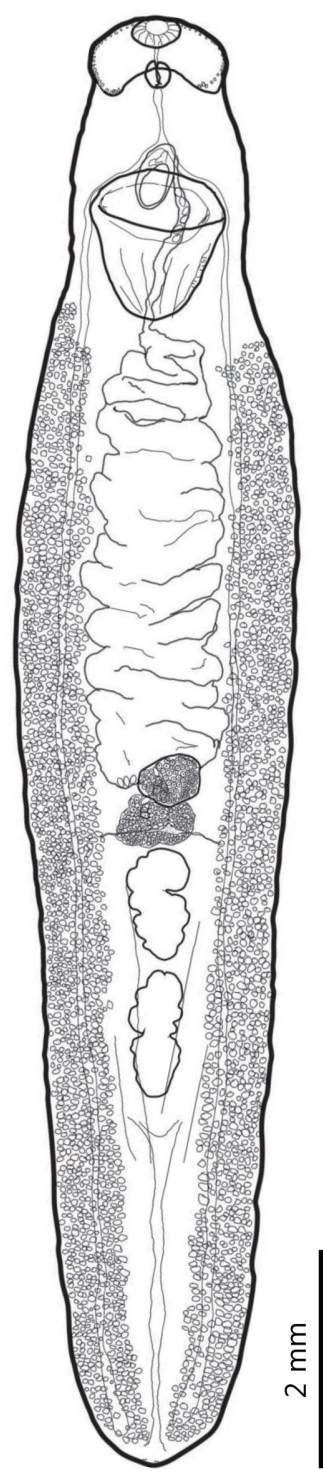

(B)

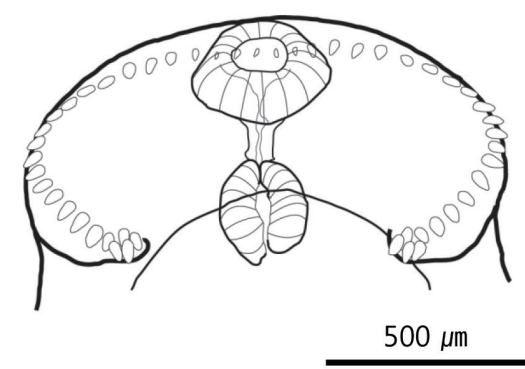

(C)

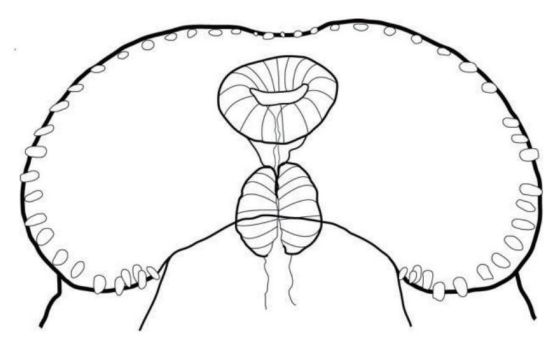

$500 \mu \mathrm{m}$

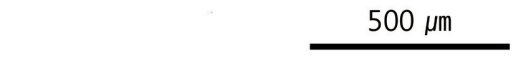

(D)

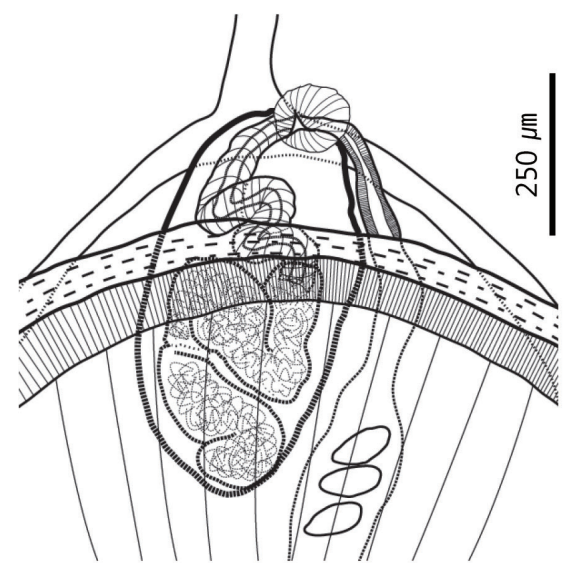

Fig. 2. Drawings of Nephrostomum ramosum specimens recovered from a cattle egret, Bubulcus ibis coromandus. (A) Whole body. (B) Head region of a specimen whose collar was lifted by the specimen fixation process. (C) Head region of a specimen with a well-positioned collar that made it possible to observe the dorsal recess. (D) Cirrus sac region containing the convoluted seminal vesicle. 
ly small, muscular, and spherical. It located behind the intestinal bifurcation. Intestinal caeca lay along both sides of the body and ran to the posterior end.

The cirrus sac projected between the intestinal bifurcation and the ventral sucker. It longer than half of the maximum width of the body. It had a long balloon shape and armed with minute spines on its distal end. Long vas deferens connected with the spherical to oval seminal vesicle. The cirrus surrounded by prostate glands (Fig. 1C). Two large tandem testes located at the posterior half of the body. Anterior testis had a horseshoe shape, while the posterior testis shaped as either a bluntended triangle or a trapezoid. The post-testicular field was short $(\mathrm{T} / \mathrm{BL}=12-19 \%)$.

Ovary small, round to oval shaped, and located slightly to the dextral side of the body. Mehlis' gland located at the median between the ovary and the anterior testis. It fitted almost exactly in the concave region of the anterior margin of the anterior testis. Vitelline follicles distributed slightly behind the pharynx to the level of the posterior testis. Vitelline reservoir located at the center of Mehlis' gland. Vitelline field had a reverse U-shape. The relative length of the uterine field very short $(\mathrm{U} / \mathrm{BL}=3-6 \%)$. Uterus slightly overlapped with Mehlis' gland and the ovary. Genital pore located anterior to the cirrus sac. The eggs yellowish brown. 108-121 (115) long and 66-74 (71) wide.

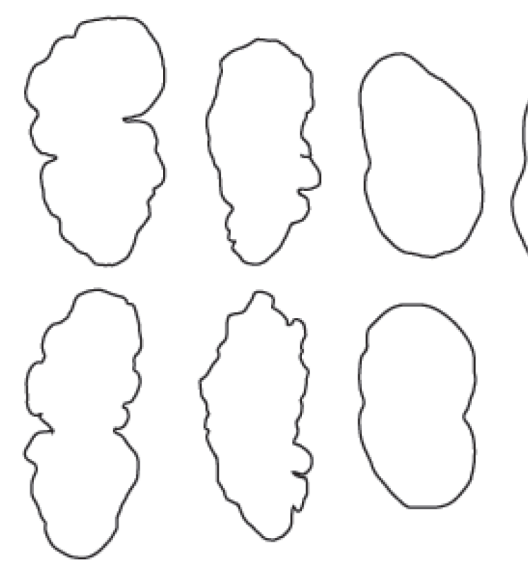

(A)
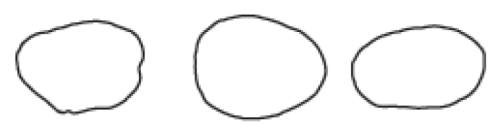

(B)
Genus Nephrostomum Dietz, 1909

Nephrostomum ramosum Sonsino, 1895

Materials examined: Six of 9 specimens collected from a $B$. ibis coromandus from Cheongju-si (city), Chungcheongbuk-do (province), Korea (GPS: $36^{\circ} 36^{\prime} 56.9^{\prime \prime} \mathrm{N} 127^{\circ} 28^{\prime} 54.9^{\prime \prime E}$ ). Two of the specimens were deposited in the NIBR (NIBR specimen numbers: KOSPIV0000221887 and KOSPIV0000221888).

The morphological characteristics were described with 6 adult specimens (Fig. 2). Morphometric measurements of their features are provided in Table 2. While all 6 worms had similar morphological characteristics, variation was also observed. Body large, elongated, and ribbon shaped. Maximum width of the body at the level of the mid-uterus region (BW/ $\mathrm{BL}=16-23 \%$ ). Tegumental spines absent (Fig. 2A). Head collar well developed, longer than wide, and reniform. Collar exhibited a dorsal recess and the ventral notch very wide. Ventral ridges well developed. Collar spines small and numbered $47-$ 50. Angle spines 4-6 pairs, comprised a double row, 40-60 (53) long and 15-32 (25) wide. The other spines arranged in a continuous row. Lateral spines 30-64 (52) long and 20-32 (25) wide. Dorsal spines relatively smaller than other spines, being 12-35 (26) long and 10-15 (13) wide. Prepharynx short. Oral sucker subterminal and located at the median region of the collar. It small and spherical. Prepharynx short. Pharynx small (somewhat similar to the oral sucker in size) and had a slight-

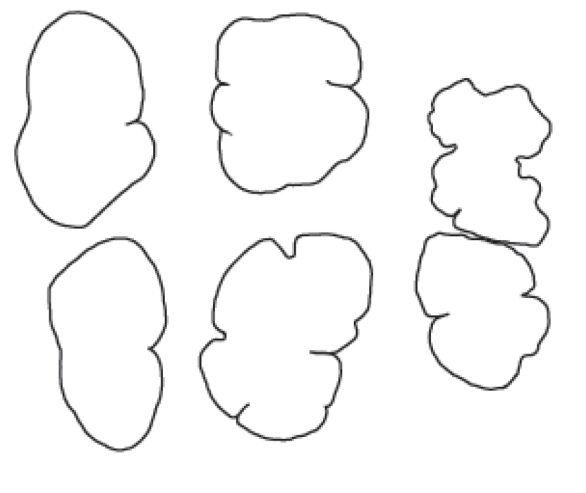

$1 \mathrm{~mm}$
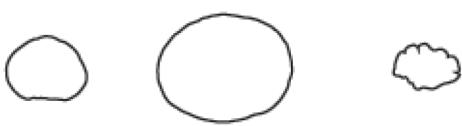

$1 \mathrm{~mm}$

Fig. 3. Morphological variation of the testes (A) and the ovary (B) of Nephrostomum ramosum. 
ly elongated oval shape (Fig. 2B, C). Forebody short (FO/ $\mathrm{BL}=9-12 \%)$. Ventral sucker well developed, muscular, and cup-shaped. Intestinal bifurcation located just anterior to the ventral sucker. Intestinal caecum reached the posterior extremity along the median region of the vitelline field. Excretory vesicle narrow and had several branches.

Cirrus sac oval and relatively small. It located anterodorsally of the ventral sucker. It composed of a long convoluted seminal vesicle that connected to convoluted cirrus (Fig. 2D). There were 2 tandem testes located 3 quarters of the way down the body. They either had an elongated oval shape, were constricted medially, or irregularly lobed (Fig. 3A). Post-testicular field very long $(\mathrm{T} / \mathrm{BL}=22-31 \%)$. Ovary generally round and small, but also showed variations in shape and size (Fig. 3B). It located slightly posterior to the equatorial region of the body. Mehlis' gland lay behind the ovary. The vitelline reservoir located at the center of Mehlis' gland. Vitelline follicles very small. They extended anteriorly to the mid-level of the ventral sucker or slightly behind the ventral sucker, and extended posteriorly to the posterior end along each side of the body. Uterine field length long $(\mathrm{U} / \mathrm{BL}=18-35 \%)$. Uterus coiled and filled with numerous eggs. Eggs yellowish brown, 92-102 (98) long and 47-67 (53) wide.

\section{DISCUSSION}

Among 3 echinostome species recovered in the present study, 2 species, namely, Pegosomum bubulcum and Nephrostomum ramosum, are the new members of Korean trematode fauna. Choe et al. [9] recently reported 3 echinostome species, i. e., Patagifer bilobus, Petasiger neocomense and Saakotrema metatestis, and they also described another echinostome species, Chaunocephalus ferox, from the oriental white stork Ciconia boyciana (in press). By the Choe et al. [9], total 14 echinostome species including E. japonicus had been reported in Korea before their studies. However, they erroneously omitted an echinostome species, Hypoderaeum conoideum from their list $[9,10]$. Accordingly, a total of 21 echinostome species including 2 by the present study are to be listed in the Korean trematode fauna.

The morphological characteristics of specimens expelled from the ball-like bulge on the liver agreed well with those of the genus Pegosomum [8]. Ratz [11] erected the genus Pegosomum by including 3 species, namely, P. asperum (Wright, 1879) Ratz, 1903, P. saginatum (Ratz, 1897) Ratz, 1903, and P. spiniferum Ratz, 1903. Thereafter, Mendheim [12] recognized 4 species of
Pegosomum as valid species, P. asperum, P. bubulcum Tubangui and Masilungan, 1935, P. saginatum, and P. spiniferum. Subsequently, Skrjabin and Bashkirova [13] recognized 3 additional valid species, namely, P. herodiae (McCallum, 1918) Skrjabin and Bashkirova, 1956, P. petrovi Kurashvili, 1949, and P. skrjabini Shakhtakhtinskaya, 1949. Although P. asperum was not mentioned by Skrjabin and Bashkirova, it was recognized as a valid species by Aleksandrova and Podgornova and they considered P. spiniferum to be its synonym [14]. In the latest publication regarding the genus Pegosomum, Unar et al. [15] recognized 5 additional species, P. indicum Saksena, 1960, P. ixobrychi Gvozdev, 1960, P. lucknowensis Pandey, 1973, P. egretti Srivastava, 1957, and P. munifi Dharejo, 2006, and they also added P. garzettae Ulnar, 2011 as a new species. Therefore, excluding P. spiniferum (which may be a synonym of $P$. asperum), 11 species were recently recognized as valid species of Pegosomum [15]. However, an earlier review by Aleksandrova suggested that on the basis of several features (body length and width ratio, number of collar spines, presence and shape of intestinal diverticula, and distribution of the vitelline follicles), only 5 species are valid, namely, P. asperum, P. saginatum, P. herodiae, P. egretti, and $P$. ixobrychi, and that the remaining species (P. spiniferum, P. skrjabini, P. petrovi, P. bubulcum, and P. ixobrychi pici) are not valid [16].

The vitelline follicles of our Pegosomum specimens differed from some of the previously described species of the genus. They were limited to the middle of the posterior testis, whereas they reach the posterior extremity in $P$. asperum, $P$. petrovi, $P$. saginatum, P. skrjabini, P. spiniferum, and P. garzettae [11-16]. In $P$. ixobrychi, they only extend to the anterior testis and members of the species have diverticula in the esophagus and intestine [17]. P. indicum, P. lucknowensis, and P. munifi, which have all been reported from Indo-Pakistan regions, also differ from our specimens in regard to vitelline distribution. Their vitelline follicles extend to the posterior end of the body $[15,18]$. Moreover, $P$. egretti has 25 spines, whereas our specimens had 27 [18]. Only $P$. bubulcum and $P$. herodiae are largely consistent with our specimens in terms of morphology $[19,20]$. Although Aleksandrova [16] considered $P$. bubulcum to be a synonym of $P$. herodiae, we do not agree with this assessment because the descriptions of $P$. herodiae were incomplete, as shown by the absence of details in the original description regarding the number of spines [20]. In addition, $P$. herodiae seems to differ from our specimens and the drawing of $P$. bubulcum in terms of the shape of the testes and their distribution [20]. The drawing of P. herodiae shows that the anterior testis is irregularly square and the posterior tes- 
tis has a somewhat blunt conical shape. Moreover, both testes were limited to a region between the intestines and did not overlap [20]. In contrast, the testes of our specimens overlapped with the intestines and their shapes were that of a horseshoe and blunt-ended trapezoid, respectively. This suggests that our specimens are not $P$. herodiae. Since the type host of $P$. bubulcum is the cattle egret B. ibis coromandus (=Bubulcus coromandus), and this was also the host of our specimens [19], we recognize the validity of $P$. bubulcum and consider our specimens to be $P$. bubulcum. Notably, there are some differences between our specimens and $P$. bubulcum in terms of distribution of the vitel- line follicles surrounding the esophagus, which in our specimens more resembles the true distribution of the vitelline follicles in $P$. herodiae [20]. However, the stained parenchyma of our specimens seemed similar to that shown in the drawing of $P$. bubulcum [19]. It is possible that the apparent distribution of vitelline follicles around the esophagus and post-pharynx region of $P$. bubulcum actually represents stained parenchyma. Finally, this is the first report detailing an armed cirrus and minute diverticula of the esophagus in P. bubulcum (Fig. 4A, B).

The flukes we recovered from the small intestines had 47-50 collar spines forming a single continuous row on a reniform
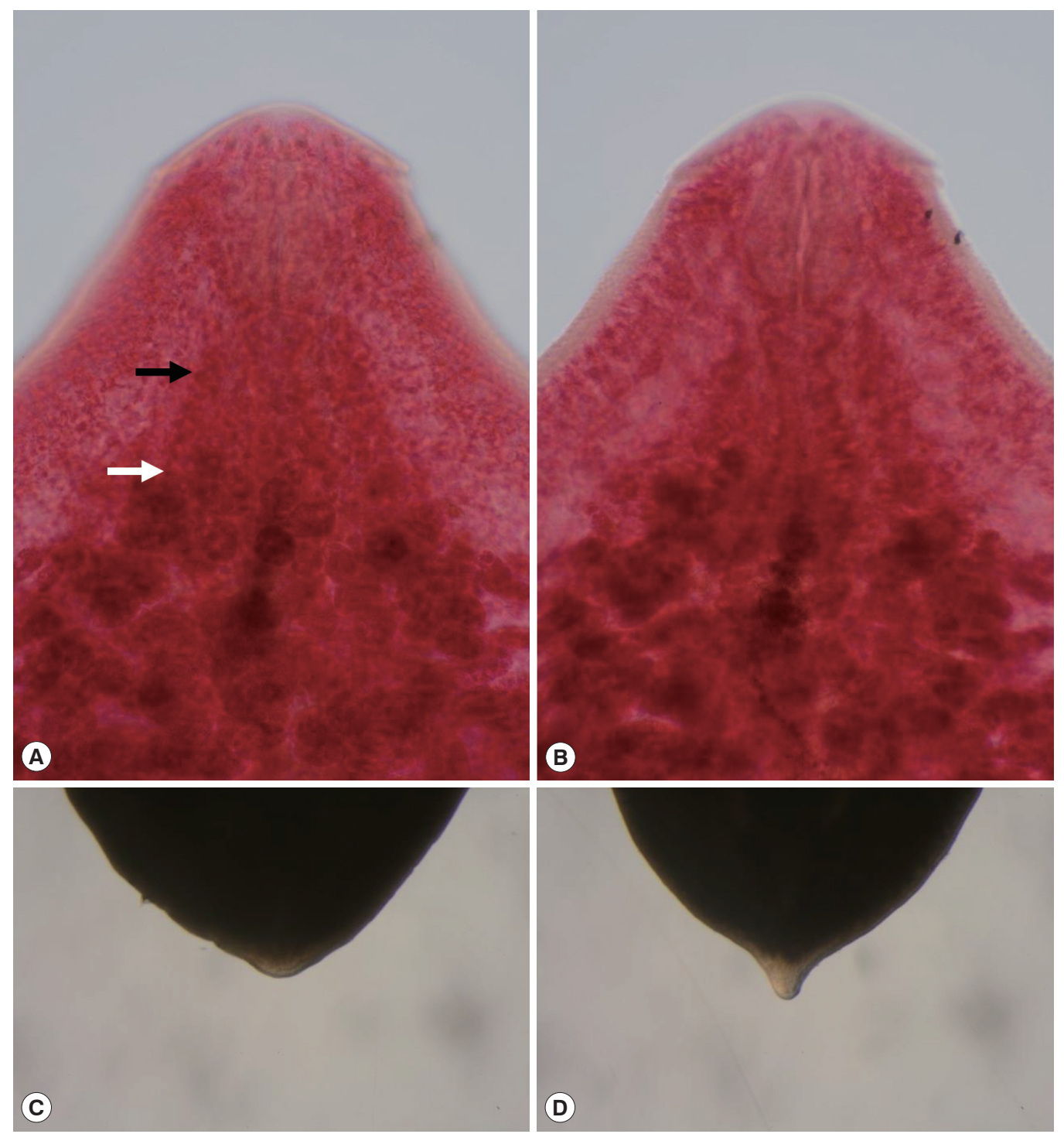

Fig. 4. Photographs of Pegosomum bubulcum (A, B) and Nephrostomum ramosum (C, D). (A) P. bubulcum. Anterior distribution of vitelline follicles. Black arrow: stained parenchyma, White arrow: true distribution of vitelline follicles. (B) Esophagus of $P$. bubulcum showing a minute diverticulum. (C) Blunt posterior end of N. ramosum. (D) Posterior end of N. ramosum that seems to be similar to that described by Ukoli [25]. 
head collar that was composed of a wide ventral notch and a shallow dorsal depression. These characteristics suggest that our specimens belong to the subfamily Nephrostominae Mendheim, $1943[8,12]$. This subfamily includes the genera Nephrostomum Dietz, 1909 and Patagifer Dietz, 1909. Only 1 species of this subfamily, Patagifer bilobus, has been recorded in Korea [9]. However, our specimens lacked the dorsal incision observed in Patagifer species and instead had a shallow depression. This suggests that our specimens may belong to the genus Nephrostomum.

Among the known species of the genus Nephrostomum, our specimens matched well with the descriptions of $\mathrm{N}$. ramosum (Sonsino, 1895) Dietz, 1909 by Skrjabin and Bashkirova [13]. Although the morphological characteristics of our specimens varied, we speculate that this reflects morphological variation within the species.

Regarding other possible species in the genus Nephrostomum, N. australe (Johnston, 1928) Mendheim, 1943 appears to be a valid species since it differs significantly from $\mathrm{N}$. ramosum in regard to the number of collar spines [12,21]. However, there is doubt concerning the validity of other reported Nephrostomum species. Odhner [22] considered Nephrostomum garzettae (MacCallum, 1904) to be a synonym of $N$. ramosum. Moreover, Tubangui [23] believed that Nephrostomum bicolanum Tubangui, 1933 differed from N. ramosum because it lacked dorsal recesses, while Prudhoe [24] regarded it as a synonym of N. ramosum. Although Skrjabin and Bashkirova [7] did not agree with Prudhoe [24], and this opinion was supported by Fischthal and Kuntz [13], our observations support the position of Prudhoe [24]. In general, we found that when the specimens were fixed, the collar lifted up and the dorsal recess overlapped with the head and oral sucker according to our light microscopic observations. This made it difficult to observe the dorsal recess (Fig. 2B). However, in 1 slide specimen that had a well-positioned collar, the dorsal recess was clearly observed (Fig. 2C). Both types of specimens were also observed by Ukoli [25], who also suggested that this variation may reflect the state of the muscles at fixation.

Nephrostomum limai Travassos, 1922, which was collected from Syrigma sibilatrix (Temminck, 1824) in South America [26], may also be a synonym of N. ramosum. In their key to the species of the genus Nephrostomum, Skrjabin and Bashkirova [13] noted that N. limai had 38 spines, which is less than the number of spines they reported for $N$. ramosum (47-51). However, this was based on the erroneous key suggested by Mendheim [12]. This error caused confusion among later research- ers, who continued to cite this erroneous number in their own reports $[27,28]$. Indeed, Travassos [26] originally noted that $N$. limai had 48 collar spines, which is consistent with the morphological variation of $N$. ramosum reported by Skrjabin and Bashkirova [13]. In addition, the description of N. limai and the drawing of the cirrus sac provided by Travassos [26] seem to resemble the morphological attributes of our specimens. Although the origin of $N$. ramosum in the New World is not clear, its history may reflect expansion of the type host, namely, the cattle egret. The cattle egret is regarded as an invasive species in the New World. Since it was already observed in the New World in the late 1800s [29], N. ramosum may have been introduced into the New World from Africa by its host at that time. It may then have spread to native hosts in the New World. N. ramosum has been found in invasive cattle egrets in both North and South America [30,31].

N. legonum Ukoli, 1967, which was found in Bubulcus ibis in Ghana, may also be spreading globally through a similar mechanism. However, this species seems to exhibit only minor differences from $N$. ramosum $[13,25]$, and may in fact be a synonym of $N$. ramosum. This notion is supported by the fact that $N$. ramosum was found in B. ibis in the nearby country of Mali, as reported by Fischthal [32]. Ukoli [25] also noted that the tail or a well-marked posterior process also differs from that of other Nephrostomum flukes. The feature was denied by Prudhoe and Hussey [33], but it was also observed in some of our specimens (Fig. 4C, D).

It is likely that Nephrostomum robustum Vigueras, 1944 is a valid species in the New World [34]. Vigueras [34] found this species in the Least Grebe Tachybatus dominicus (=Colymbus dominicus) in Havana, Cuba. Although he did not assess the taxonomy of the species, his drawings suggest that it is not a synonym of N. ramosum. The species had all of the key characteristics of the genus Nephrostomum and a collar spine number (50) similar to N. ramosum; however, it has a posteriorly tapered body whose maximum width is at the ventral sucker region [34]. In contrast, N. ramosum has a ribbon-shaped body whose maximum width is located between the uterus and testes regions. In addition, the drawing of N. robustum indicates it has a shorter uterine field (7\%) than $N$. ramosum (18-35\% in the present study). Therefore, we regard $N$. robustum as a valid species.

Another Nephrostomum species reported from the New World, N. sinchirocai Ibáñez, 1966 is recorded from a snowy egret, Egretta thula (=Leucophoyx thula) in Peru [35]. Ibáñez [35] considered his specimen a valid species based on the smaller 
number of collar spines $(\mathrm{n}=26)$ in comparison to other species of the genus Nephrostomum. However, the description seems to be based on a specimen of poor condition, and his drawing shows that the angle spines and some of the lateral spines are absent [35]. Loss of spines in echinostome specimens is a common phenomenon when treating specimens in poor condition (personal communication). As a consequence, we believe that the species could be a synonym of $\mathrm{N}$. ramosum if we disregard the possibility that it is a genuine morphology described with fresh specimens. N. skrjabini is characterized by the presence of tegumental spines, but is also regarded as a synonym of $\mathrm{N}$. ramosum [36]. Although we did not observe tegumental spines in our specimens, the fact that Karyakarte [27] observed minute spines on the body surface of juvenile and young adult $\mathrm{N}$. ramosum specimens supports the notion that $N$. skrjabini is a young adult of $N$. ramosum. Ukoli [25] also found tegumental spines on the metacercariae of $N$. ramosum. It suggested the species resembles $N$. ramosum and $N$. bicolanum, but differs in the shape of the testes and ovary [36], and therefore N. skrjabi$n i$ could also be a synonym of $N$. ramosum. The shape of the organs also varied in the present study.

The taxonomic status of Nephrostomum species in the IndoPakistan region may be more problematic than of species in other regions. To our knowledge, 7 species of Nephrostomum flukes have been reported to date from the Indo-Pakistan region. According to Kalikabad and Bilqees [37], N. dubashi is only distinguishable from other species by the number of collar spines (27-34). However, N. reticulatum Karyakarte, 1969 and N. chandigarensis Gupta and Mehrotra, 1970 are already regarded as synonyms of $\mathrm{N}$. ramosum [38-40]. The taxonomic status of the other 4 species (N. dollfusi, N. guptai, N. udaipurensis, and $N$. oderolalensis) does not seem to have been discussed previously. We believe that they could be synonyms of $N$. ramosum because they differ only mildly from this species. The authors describing these 4 Nephrostomum species all suggested that the distinctive characteristics of each species were the number of collar spines, the shape of the testes and ovary, and the distribution of vitelline follicles. However, these features of the 4 Nephrostomum species all fall within the range of variation observed in our specimens, all of which were recovered at the same time from a single host. The number of spines in our specimens ranged from 47 to 50, the ovary and testes had irregular shapes (Fig. 3), and the distribution of vitelline follicles varied from posterior to mid-level or slightly behind of the ventral sucker. Therefore, unless our case in- volved multiple infections with at least 3 Nephrostomum species, it seems quite possible that the remaining 4 Nephrostomum species reported from the Indo-Pakistan region are also synonyms of $\mathrm{N}$. ramosum. This notion is supported by the fact that their type hosts were Bubulcus ibis, which was also the host of our specimens. Moreover, the type locality of each species is not very far from that of other species collected from the IndoPakistan region.

N. dollfusi was originally found in Bubulcus ibis in the Renital and Melonigaj area, Jabalpur, India, and was initially described as 2 different species, namely, Paryphostomum dollfusi Agarwal, 1959 and P. bubulcusi Agarwal, 1959 [41]. However, Srivastava [42] regarded $P$. bubulcusi as a synonym of $P$. dollfusi, and Kostadinova and Gibson [43] later placed the species in the genus Nephrostomum on the basis of its morphological characteristics, namely, 46-47 spines arranged in a single row, expansion of the vitelline follicles, and an unarmed tegument. We agree with Kostadinova and Gibson. However, since the species does not exhibit any specific differences from $N$. ramosum, it seems likely that this species is also a synonym of $\mathrm{N}$. ramosum.

Gupta and Singh [38] suggested a new species, N. guptai Gupta and Singh, 1986, on the basis of its slightly lobed ovary, its highly lobed testes, and the distribution of vitelline follicles. However, the ovary was not clearly lobed in their drawing, while the other 2 characteristics were observed in some of our specimens. In addition, the description of N. guptai was based on only 1 mature and 5 immature specimens [38]. This sample may be too small to adequately reflect the variation of the species. Prior to this study, one of the authors also suggested another new species, N. udaipurensis Gupta, 1983, which was found in Bubulcus ibis in Udaipur, Rajasthan, India [38]. However, this new species was not mentioned further in their published reports, although they did correctly list the other previously reported species in the genus Nephrostomum [39]. Furthermore, the morphological characteristics of $N$. udaipurensis do not differ markedly from those of $N$. guptai $[38,39]$ or N. ramosum. Therefore, we consider that both N. guptai and N. udaipurensis are synonyms of $N$. ramosum.

The description and drawing of the Pakistan species N. oderolalensis Khan and Ghazi suggest that the specimens were in poor condition [28]. In addition, their publication had a number of discrepancies: the number of collar spines varied from 40-48 in the abstract, 40-44 in the description, and 4044 and 40-46 in the remarks [28]. Moreover, we could not detect any marked specific differences between $N$. oderolalensis 
and N. ramosum. While Khan and Ghazi [28] noted that the number of spines, shape of the ovary, and distribution of vitelline follicles of $\mathrm{N}$. oderolalensis differed from those of other Nephrostomum species, these features fall in the range of variation shown by N. ramosum and our specimens. We therefore regard $N$. oderolalensis as a synonym of $N$. ramosum.

Although we indicated that $N$. dubashi is distinguishable from other species of Nephrostomum by the number of collar spines mentioned above, the true taxonomic status of the species does not seem to differ from that of other synonyms of N. ramosum. Kaikabad and Bilqees [37] suggested their specimens differed from other species of Nephrostomum, mainly by possession of 27-34 collar spines and a poorly developed cirrus sac. However, spines on the ventral lappets were absent in their drawing [37], and this spine absence is likely to have been due to observations of specimens in poor condition as in the case of N. sinchirocai [35]. If the absence of spines on the ventral lappets of both $N$. dubashi and N. sinchirocai is a genuine morphological character of the species, then this trait needs to be discussed at the genus level. We believe that the absence of spines on ventral lappets and poorly observed cirrus sac of $N$. dubashi were a result of observations of specimens in poor condition, and therefore regard N. dubashi as a synonym of N. ramosum. Additionally, N. dubashi was recorded from an unknown bird in Sindh, Pakistan [37], which was also the type location of another synonymized species, $N$. oderolalensis [28].

In conclusion, we identified $P$. bubulcum and $N$. ramosum from a cattle egret, B. ibis coromandus, on the basis of morphological observations. Moreover, comparison of our specimens with previously reported species of the genus Nephrostomum led us to the taxonomic opinion that several species of Nephrostomum, namely, N. bicolanum, N. changarensis N. dollfusi, N. dubashi, N. guptai, N. legonum, N. limai, N. oderolaensis, N. reticulatum, N. sinchirocai, N. skjrabini, and N. udaipurensis are possibly synonyms of N. ramosum. Among the species that resemble N. ramosum morphologically, especially in regard to the number of collar spines (4751 ), we only recognized the validity of N. robustum. Another species did not exhibit distinct differences regarding morphometric comparisons and estimated proportions of standard structures relative to the body length (Table 2). However, our conclusions are limited by the fact that they are based only on morphological comparisons. Molecular biological comparisons are needed to confirm these conclusions. This report describes the first case of $P$. bubulcum and N. ramosum infection of B. ibis coromandus in Ko- rea. This is the first time both flukes and associated genera have been reported as part of the parasite fauna of Korea.

\section{ACKNOWLEDGMENTS}

This work was supported by a grant from the National Institute of Biological Resources (NIBR), which is funded by the Ministry of Environment (MOE) of the Republic of Korea (NIBR no. 2013-02-001 and 2014-02-001). One of the authors (Seongjun Choe) was supported by Graduate Program for the Undiscovered Taxa of Korea (NIBR201524202). The parasite materials used in this study were provided by the Parasite Resource Bank of the National Research Resource Center (2012-0000037) of the Republic of Korea. The authors are also grateful to Philippe Vieira Alves, Programa de Pós-Graduação em Biologia Animal, Universidade Federal Rural do Rio de Janeiro, Brazil, for providing useful literature.

\section{CONFLICT OF INTEREST}

We have no conflict of interest related to this work.

\section{REFERENCES}

1. Park JG. Identification guide to birds of Korea, No. 12, Checklist of organisms in Korea. Nature and Ecology. 2014, pp 1-125.

2. Kim HK. Biology of gray heron and egrets. J Korean Res Inst Bet Liv 1969; 2: 69-81.

3. Murata K, Noda A, Yanai T, Masegi T, Kamegai S. A fatal Pegosomum sp. (Trematoda: Echinostomatidae) infection in a wild cattle egret (Bubulcus ibis) from Japan. J Zoo Wild Med 1998; 29: 78-80.

4. Uchida A, Uchida K, Kawakami Y, Nagatomo M, Shen M, Ooi H. A helminthological survey of parasites in the waterfowl of Kanagawa Prefecture, Japan. J Jpn Vet Med Assoc 2005; 58: 127131.

5. Uchida A, Uchida K, Itagaki H. Check list of helminth parasites of Japanese birds. Jpn J Parasitol 1991; 40: 7-85.

6. Yoshino T, Nakamura S, Endoh D, Onuma M, Osa Y, Teraoka H, Kuwana T, Asakawa M. A helminthological survey of four families of waterfowl (Ardeidae, Rallidae, Scolopaciadae and Phalaropodidae) from Hokkaido, Japan. J Yamashita Inst Ornithol 2009; 41: 34-41.

7. Fischthal JH, Kuntz RE. Some digenetic trematodes of birds from Taiwan. Proc Helminthol Soc Wash 1976; 43: 65-79.

8. Kostadinova A. Family Echinostomatida Looss, 1899. In Jones A, Bray RA, Gibson DI eds, Keys to the Trematoda. Volume 2. Wallingford, UK. CAB International and the Natural History Museum. 2005, pp 9-64. 
9. Choe S, Lee D, Park H, Oh M, Jeon HK, Lee Y, Na KJ, Kim Y, Lee $\mathrm{H}$, Eom KS. Three echinostome species from wild birds in the Republic of Korea. Korean J Parasitol 2014; 52: 513-520.

10. Jang DH. Study on the intestinal helminths of chicken. J Korean Vet Assoc 1958; 2(2): 149-155.

11. Ratz I. Un genre nouveau de Fasciolides. Ann Mus Hungar 1903; 1: 413-432.

12. Mendheim H. Beiträge zur Systematik und Biologie der Familie Echinostomatidae. Archive für Naturgeschichte 1943; 12: 175302.

13. Skrjabin KI, Bashkirova EY. Family Echinostomatidae Dietz, 1909. In Skrjabin KI ed, Trematodes of Animals and Man. Osnovy Trematodologii 12. Izdatel'stvo Akademii Nauk SSSR, Moscow. 1956, pp 53-930.

14. Aleksandrova OV, Podgornova GP. Taxonomical analysis of Pegosomum asperum and P. saginatum (Trematoda, Echinostomatidae). Parazitologiya 1978; 12: 413-417.

15. Unar MS, Shaikh AA, Khan MM, Channa MA. Pegosomum garzettae n. sp (Digenea: Echinostomatidae) from gallbladder of little egret Egretta garzetta (Aves: Ardeidae) of Jamshoro, Sindh, Pakistan. Parasitology 2011; 51: 143-148.

16. Aleksandrova OV. Revision of the species composition of the genus Pegosomum (Trematoda, Echinostomatidae). Zool Zhurnal 1978; 57: 827-833.

17. Gvosdev EV. New species of fluke Pegosomum ixobrychi sp. nov. from Ixobrychus minutus L. Helminthologia 1960; 2: 83-86.

18. Chen HT. Fauna Sinica. Platyhelminthes, Trematoda, Digenea (I). Beijing, China. Science Press. 1985, pp 1-697 (in Chinese).

19. Tubangui MA, Masilungan VA. Trematode parasites of Philippine vertebrates, VII. Phil J Sci 1935; 58: 435-446.

20. MacCallum GA. Notes on the genus Telorchis and other trematodes. Zoopathologica 1918; 1: 81-98.

21. Johnston TH. New trematodes from the Australian water-hen Gallinula tenebrosa. Rec S Australian Mus 1928; 4: 135-142.

22. Odhner T. Nordostafrikanische Trematoden, grösstenteils vom Weissen Nil. I. Fascioliden. Result of the Swedish Zoological Expedition to Egypt and the White Nile 1901 under the direction of LA Jägerskiöld 23A. K.W. Appelberges Boktryckeri, Uppsala, Sweden. 1910, p 1-169.

23. Tubangui MA. Trematode parasites of Philippine vertebrates, VI. Descriptions of new species and classification. Phil J Sci 1933; 52: 167-198.

24. Prudhoe SI. On some trematodes from Ceylon. Mag Nat Hist 1944; 11: 1-13.

25. Ukoli FMA. On the anatomy, growth and development in the definitive host of Nephrostomum legonum n. sp., (Trematoda: Echinostomatidae). Nigerian J Sci 1967; 1: 217-231.

26. Travassos L. Informacoes sobre a fauna helminthological de Matto Grosso. Trematoda II. Mem Inst Oswaldo Cruz 1938: 33; 461-468.

27. Karyakarte PP. Nephrostomum reticulatum sp. N. (Trematoda: Echinostomatidae) from the egret, Bubulcus ibis (Linnaeus) in
India. Riv Parassitol 1969; 30: 91-84.

28. Khan A. Ghazi RR. Nephrostomum oderolalensis n. sp. (Trematoda: Digenea) in cattle egret (Bubulcus ibis L.) from Sindh, Pakistan. Int J Biol Biotech 2011; 8: 487-490.

29. Wetmore A. An early record of the cattle egret in Colombia. Auk 1963; 80: 547.

30. Stuart JJ, Dismukes JF, Dixon CF. Endoparasites of the cattle egret (Bubulcus ibis) in Alabama. J Parasitol 1972; 58: 518.

31. Fischthal JH, Whittaker FH. Two digenetic trematodes from the cattle egret, Bubulcus ibis (L.), from Puerto Rico. J Parasitol 1977; 63: 491.

32. Fischthal JH. Some digenetic trematodes of birds from Central and West Africa. Rev Zool Africaine 1977; 91: 675-680.

33. Prudhoe S, Hussey CG. Some parasitic worms in freshwater fishes and fish-predators from the Transvaal, South Africa. Zool Afr 1977; 12: 113-147.

34. Pérez Vigueras I. Trematodes de la super-familia Echinostomatoidea, con descripcion de siete especies nuevas de Cuba. Rev Univ Habana 1944; 55-57: 221-234.

35. Ibáñez HN. Contribucion al conocimiento de la fauna helmintologica peruana. "Nephrostomum sinchirocai" sp. n. (Trematoda, Echinostomatidae). Rev Brasil Biol 1966; 26: 93-96.

36. Kasimov GB, Vaidova SM, Felizullaev NA. A new trematode from Bubulcus ibis. Papers on Helminthology presented to Academician KI Skjrabin on his 80th birthday 1958; 145-147.

37. Kaikabad SH, Bilqees FM. Nephrostomum dubashi n. sp. from a bird of W. Pakistan. In Bilqees FM, Saeed R, Rehana R, Khatoon A, Kaikabad SH eds, Helminth parasites of some vertebrates chiefly from fishes of West Pakistan. Agric Res Council Govt of Pakistan, Karachi. 1972, pp 97-99.

38. Gupta PC. Nephrostomum udaipurensis n. sp. (family - Echinostomatidae Poche, 1026) from Bubulcus ibis (Linn.). Indian J Parasitol 1983; 7: 43-45.

39. Gupta PC, Singh RB. Digenetic trematode parasites of fishes and birds. I. On a new trematode Nephrostomum guptai n. sp. (familyEchinostomatidae Poche, 1926) from an avian host, Bubulcus ibis (Linn.) from Unnao (U.P.). Indian J Helminthol 1986; 37: 121126.

40. Sahay S, Sahay U, Verma DK. On Nephrostomum ramosum (Sonsino, 1859) Dietz, 1909 from a new host at Ranchi (Chotanagprur). Indian J Helminthol 1987; 39: 12-127.

41. Agarwal SM. Studies on two new species of the genus Paryphostomum (Dietz, 1909), (Trematoda: Echinostomatidae) from Bubulcus ibis. Indian J Helminthol 1959; 10: 19-30.

42. Srivastava CB. The fauna of India and adjacent countries. Platyhelminthes. Vol. I. (Suppl.) Trematoda - Digenea. Zoological Survey of India, Calcutta, 1982, pp 1-163.

43. Kostadinova A, Gibson DI. Redescriptions of two echinostomes from birds in Paraguay, with comments on Drepanocephalus Dietz, 1909 and Paryphostomum Dietz, 1909 (Digenea: Echinostomatidae). Sys Parasitol 2002; 53: 147-158. 